\title{
An overview on impact and application of microorganisms on human health, medicine and environment
}

\author{
Kazi Madina Maraz and Ruhul Amin Khan * \\ Institute of Radiation and Polymer Technology, Atomic Energy Research Establishment, Savar, Dhaka, Bangladesh.
}

GSC Biological and Pharmaceutical Sciences, 2021, 14(01), 089-104

Publication history: Received on 10 June 2021; revised on 15 July 2021; accepted on 17 July 2021

Article DOI: https://doi.org/10.30574/gscbps.2021.16.1.0200

\begin{abstract}
Microorganisms or microbes are microscopic organisms that exist as unicellular, multicellular, or cell clusters. Microorganisms are widespread in nature and are beneficial to life, but some can cause serious harm. They can be divided into five major types: Bacteria, Archaea, Fungi, Protozoa, and Viruses. Microbes are everywhere in the biosphere, and their presence invariably affects the environment that they are growing in. Microorganisms are beneficial in producing oxygen in environment, decomposing organic material, medicine, providing nutrients for plants, and maintaining human health, but some can be pathogenic and cause diseases in plants and humans. They perform a key role and act as main engineers in governing all ecological processes. They act as universal catalyst and provide ecological transformations. Regardless of whether they influence human health and welfare favorably or unfavorably, microorganisms are capable of profound influences on life. That is to say, it is an integral part of our lives, and therefore acquiring knowledge about it should also be essential and the main thing.
\end{abstract}

Keywords: Bacteria; Fungi; Protozoa; Viruses; Microbiological Analysis

\section{Introduction}

Every surface of the human body exposed to the environment is colonized by a diverse microbial community called the microbiota. This community includes bacteria, fungi, and viruses, and these microorganisms are thought to outnumber human cells. The microbiota associated with the rhizosphere is responsible for crucial processes. Understanding how the plant and its bacterial community interact is of great importance to face the upcoming agricultural and viticultural challenges. The continuous improvement of cultivation independent techniques is driving a paradigm shift in the field of biology; the expression of a specific phenotype is no longer determined solely by the interaction between genotype and environment but has to take into account the host-associated microorganisms [1-3]. Microorganisms are environmentally, economically, and socially important. These are being exploited for a wide range of products, enzymes, probiotics, biofuels like bioethanol, hydrogen gas, etc. from centuries. Currently, on an industrial scale, these microbes are playing important roles to clean up toxic waste. Microorganisms and their enzymes are chiefly involved in the breakdown of organic materials in wastewater. They perform a key role and act as main engineers in governing all ecological processes [4]. The aim of review to express current trend the Impact and application/role of microorganisms on Human health, Medicine and to contribute Environmental background which is identified gaps in this thematic area. Presently, it is hot research area because microorganisms are eco-friendly and promising valuable genetic material to solve environmental threats and human health life.

\footnotetext{
${ }^{*}$ Corresponding author: Ruhul Amin Khan

Institute of Radiation and Polymer Technology, Atomic Energy Research Establishment, Savar, Dhaka, Bangladesh. 


\section{Microorganisms}

Microorganisms, due to their unique ability to adapt to extreme conditions imposed by oligotrophy (low nutrients), temperature, $\mathrm{pH}$, pressure, and radiation, among others, have so far been found in every environment imaginable. Though molecular sequencing of genomes and metagenomes has revealed immense diversity within the category microorganisms, now known to represent three distinct domains of life, Bacteria, Archaea and Eucarya, and perhaps hiding even more undiscovered types including a potential fourth domain according to recent suggestions considering them together has scientific advantages [4-5]. Thus, methods first applied to bacteria and archaea for direct characterization of natural communities are increasingly being applied also to uncultured eukaryotes and viruses and even the attached viruses of uncultured eukaryotes in such communities. When we talk about a microbial community, it is a community of microorganisms in the widest sense we must study, complete with bacteria, archaea, fungi, algae or protist varieties of eukaryotes, and all their accompanying viruses. So, microbial diversity is truly staggering, yet all these microbes can be grouped into five major types: Bacteria, Archaea, Fungi, Protozoa and Viruses [6-7]. In fact, microorganisms are pioneer colonizers and have, over geologic time, had a profound influence on the climate and environments found on Earth. It is still unknown what are the limits of microbial life. Bacteria have been successfully recovered even from the hyperarid core of the Atacama Desert in Chile shown in the picture above [8]. Figure 1 shows the evolutionary timeline of life on Earth.

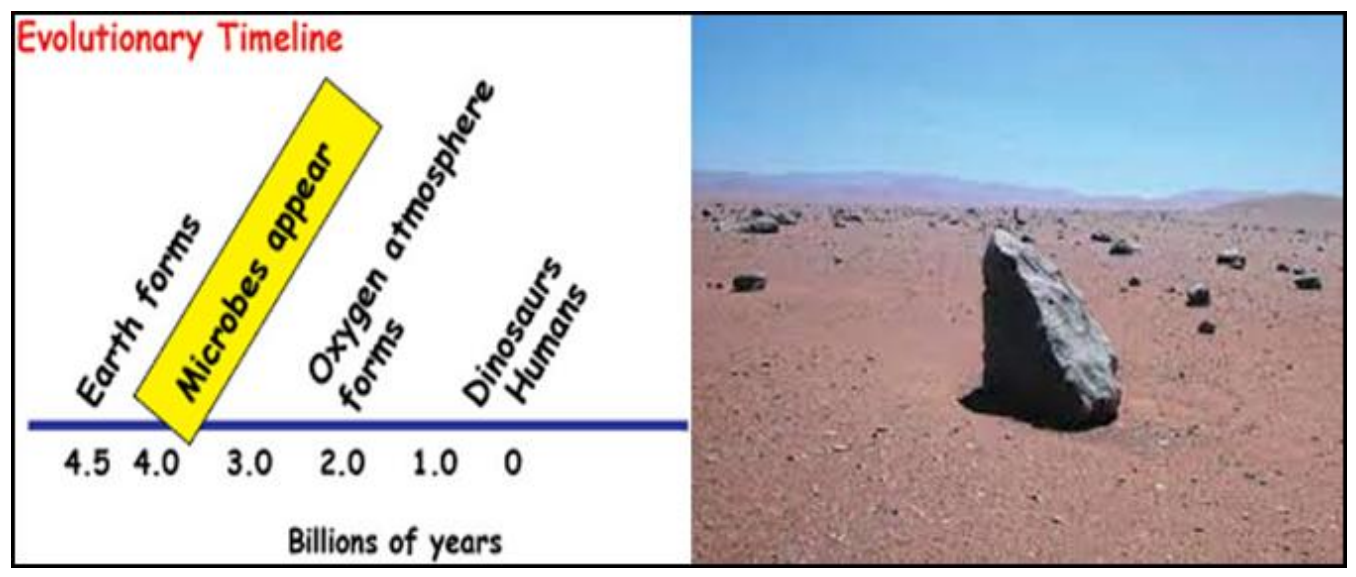

Figure 1 An evolutionary timeline showing the approximate appearance of life on Earth from 4.5 billion years ago to the present time Photo courtesy: Julio L. Betancourt, U.S. Geological Survey

\section{The Main types of Microorganisms}

\subsection{Bacteria}

The bacteria are the least structurally complex of the microorganisms but offer the greatest metabolic flexibility and have the greatest diversity.

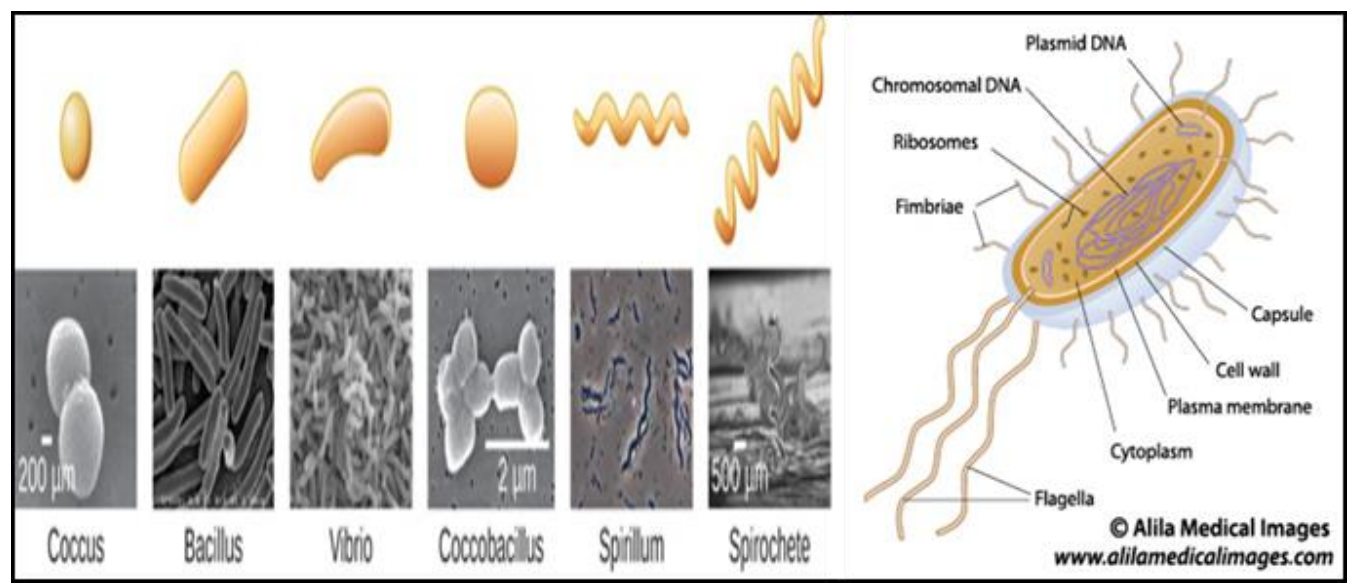

Figure 2 Types of Bacteria and their shapes 
It is estimated that there are more than 50 bacterial phyla based on the analysis of the conserved 16S rRNA sequence. Bacteria are found in nearly every habitat on earth, including within and on humans. Most bacteria are harmless or helpful, but some are pathogens, causing disease in humans and other animals. Bacteria are prokaryotic because their genetic material (DNA) is not housed within a true nucleus. Most bacteria have cell walls that contain peptidoglycan [9].

Bacteria are often described in terms of their general shape. Common shapes include spherical (coccus), rod-shaped (bacillus), or curved (spirillum, spirochete, or vibrio). In the laboratory, bacteria average $0.5-1 \mu \mathrm{m}$ in diameter and 1$2 \mu \mathrm{m}$ in length and have the basic composite. They are generally characterized by high rates of replication (E. coli can replicate by binary fission in less than 10 minutes), high surface area-to-volume ratio, and genetic malleability. The relative simplicity of the bacterial cell allows it to rapidly respond and adapt to changing environmental conditions [910]. Figure 2 represented the types of Bacteria and their shapes.

\subsection{Archaea}

Archaea are microbes that look somewhat similar to bacteria in size and shape under the light microscope but they are actually genetically and biochemically quite different. They appear to be a simpler form of life, and may in fact be the oldest form of life on Earth. Based on their habitat, all Archaeans can be divided into the following groups: methanogens (methane-producing organisms), halophiles (archaeans that live in salty environments), thermophiles (archaeans that live at extremely hot temperatures), and psychrophiles (cold-temperature Archaeans). Archaeans use different energy sources like hydrogen gas, carbon dioxide, and sulphur. Archaea were originally thought to only inhabit extreme environments, leading to the term extremophiles, but more recently they have been shown to exist in a variety of normal or nonextreme environments. For example, identified similar archaea from nonextreme environments in four Chinese and American pristine soils. Archaea are also found in high numbers in cold marine environments [11]. Table 1 shows the key structural differences between archaea and bacteria.

Table 1 Key structural differences between archaea and bacteria are identified [8]

\begin{tabular}{|l|l|l|}
\hline \multicolumn{1}{|c|}{ Structure } & \multicolumn{1}{|c|}{ Archaea } & \multicolumn{1}{c|}{ Bacteria } \\
\hline Lipid & $\begin{array}{l}\text { Glycerol based phospholipids but stereochemistry of the } \\
\text { glycerol is opposite that of bacteria and eukaryotes }\end{array}$ & $\begin{array}{l}\text { Glycerol } \\
\text { phospholipids }\end{array}$ \\
\hline Membranes & Composed of glycerol ether lipids & $\begin{array}{l}\text { Composed of glycerol ester } \\
\text { lipids }\end{array}$ \\
\hline Cell wall & $\begin{array}{l}\text { Lacks peptidoglycan, contains surface layer proteins or S- } \\
\text { layer }\end{array}$ & Peptidoglycan and S-layer \\
\hline Flagella & Resembles Type IV pili & Resembles Type III pili \\
\hline Chromosome & One circular chromosome & One circular chromosome \\
\hline
\end{tabular}

Also of interest is the fact that the archaean lipids are based on a 5-carbon isoprene unit that is also present in rubber. Nonextreme archaea have been found in a variety of environments including soil, seawater, or even sewage. No pathogenic archaea have yet been isolated [12].

\subsection{Fungi}

Fungi (singular: fungus) are eukaryotes. Some multicellular fungi, such as mushrooms, resemble plants, but they are actually quite different. Fungi are not photosynthetic, and their cell walls are usually made out of chitin rather than cellulose. A light micrograph with a clear background and blue cells. A long row of cells forms a central strand. Attached to this are clusters of many spherical cells. Each cell is approximately $5 \mu \mathrm{m}$ in size and contains a nucleus. Although bacteria may represent the most abundant microorganisms in terms of numbers of individuals, the fungi, which are a physically larger group of eucaryotic microorganisms, have the greatest biomass. Conservatively, 1.5 million fungal species are estimated to exist, with only 7\% of them identified so far. The identification of fungi has been based on morphology, spore structure, and membrane fatty acid composition. However, similar to use of the 16S rRNA gene for identification and classification of bacteria, the analogous eucaryotic gene, the 18S rRNA gene, is being used for fungal identification. Fungi can be divided into three general groups based on morphological descriptions: molds, mushrooms, and yeasts. Slime molds with phenotypic characteristics of both fungi and protozoa will be discussed later. Molds, such 
as Aspergillus, Penicillium, Rhizopus, and Pilobolus, are filamentous fungi which are found in many fungal phyla. Each filamentous fungal cell is called a hypha (plural hyphae), which grows in masses to form tufts of hyphae or mycelia [13].

\subsection{Protozoa}

Protozoa are microscopic unicellular eukaryotes that have a relatively complex internal structure and carry out complex metabolic activities. All protozoa rely on water, and as such they are most commonly observed in freshwater and marine habitats, although some are terrestrial in moist soils and others are exclusively found in the gastrointestinal tracts of animals. Some protozoa form cysts or oocysts as part of a complex life cycle. Similar to spores in bacteria and fungi, cysts can increase the survival of the organism. The Protozoa are considered to be a subkingdom of the kingdom Protista. More than 50,000 species have been described, most of which are free-living organisms; protozoa are found in almost every possible habitat. The 18S rRNA based classification being used for eucaryotic microorganisms has revealed fundamental genetic differences among the protozoa. Protozoa are unicellular eukaryotes. It has emerged that the single-celled protozoa are a polyphyletic group of eucaryotic microorganisms. Most parasitic protozoa in humans are less than $50 \mu \mathrm{m}$ in size. The smallest (mainly intracellular forms) are 1 to $10 \mu \mathrm{m}$ long, but Balantidium coli may measure $150 \mu \mathrm{m}$. Between 1674 and 1716, he described, in addition to free-living protozoa, several parasitic species from animals, and Giardia lamblia from his own stools. Virtually all humans have protozoa living in or on their body at some time, and many persons are infected with one or more species throughout their life. In 1985 the Society of Protozoologists published a taxonomic scheme that distributed the Protozoa into six phyla. Two of these phyla such as Sarcomastigophora and Apicomplexa, contain the most important species causing human disease. This scheme is based on morphology as revealed by light, electron, and scanning microscopy. Dientamoeba fragilis, for example, had been thought to be an ameba and placed in the family Entamoebidae. However, internal structures seen by electron microscopy showed that it is properly placed in the order Trichomonadida of flagellate protozoa [8, 10, 14]. Figure 3 represented the fine structure of a protozoan parasite, Typanosoma evansi.

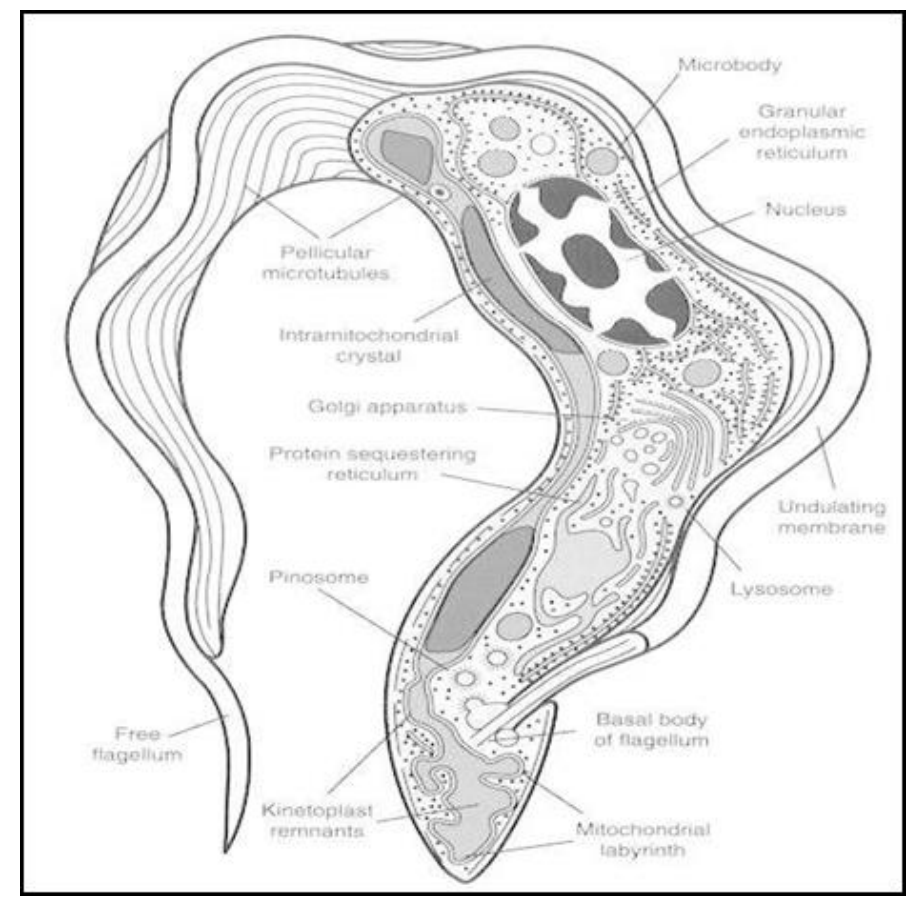

Figure 3 Fine structure of a protozoan parasite, Typanosoma evansi, as revealed by transmission electron microcopy of thin sections. (Adapted from Vickerman K: Protozoology. Vol. 3 London School of Hygiene and Tropical Medicine, London, 1977.)

\subsection{Viruses}

Viruses are acellular microorganisms, which means they are not composed of cells. Essentially, a virus consists of proteins and genetic material, either DNA or RNA, but never both, that are inert outside of a host organism. Viruses are a group of biological entities consisting of a nucleic acid encapsulated within a protein coat known as the capsid in various different sizes and morphologies. The role of viruses of microorganisms in natural ecosystems and population microbiology at a global scale, understanding bacteria, archaea, and eukaryote microorganisms including their genomes and their ecology also needs understanding of their viruses and interactions with them at a molecular level. Viral nucleic 
acids can consist of single or double stranded DNA or RNA. Although some viruses do contain a few enzymes, they are obligate parasites that have no metabolic capability and rely on host metabolism to produce viral parts that selfassemble. The growth cycle of a virus can be described in five steps: (1) adsorption; (2) penetration; (3) replication; (4) maturation; and (5) release. The interactions of bacteriophage with a procaryotic host are diverse. Lytic phage are predators of prokaryotes. In contrast lysogenic and chronic infections are actually a parasitic interaction that could be described as mutualism $[10,15-16]$.

\section{Impact of Microorganism}

Microbes are omnipresent in the biosphere, and their presence invariably affects the environment in which they grow. The effects of microbes on their environment can be beneficial or harmful or inapparent with regard to human measure or observation [17].

\subsection{Bacterial Impacts}

Formation of bacterial biofilms is a complicated phenomenon in which genetic mechanisms and various other factors are involved (environmental change, nutrients, gene regulation and surface attachment) [18].

\subsubsection{Some substance of bacterial biofilms}

- Among these factors' characteristics of substratum and surface of bacterial cells are most important because, there is mounting evidence a regulation of genes occurs in the attaching cells upon initial interaction with the substratum and the surface could be a dead or living tissue, or any inert surface [19].

- Sessile bacterial biofilm cells release antigens and stimulate the production of antibodies, but the antibodies are not effective at killing bacteria within biofilms and may cause immune complex damage to the surrounding tissues. Even in individuals with excellent cellular and humoral immune reactions, biofilm infections are rarely resolved by the host defense mechanisms [20].

- Antibiotic therapy typically reverses the symptoms caused by planktonic cells that are released from the biofilms but fails to kill them that lead to antibiotic resistance [21].

Bacterial biofilms are responsible for about $80 \%$ of infectious diseases affecting animals and human from those diseases approximately $61 \%$ of human biofilm infections are zoonotic origin [22].

\subsubsection{Impact of gram-positive bacteria}

Some gram-positive bacteria, such as Bacillus and Clostridium spp., produce endospores-multilayered structures capable of withstanding adverse conditions including radiation, UV light, heat, desiccation, low nutrients, and chemicals-to ensure the survival of the cell. Endospores are environmentally significant because they can remain in a metabolically dormant state for long periods only to germinate and reactivate when conditions become favorable for growth. Some endospores have remained viable for 100,000 years [10]. In gram-positive bacteria, the cell wall is made up of many stacked layers of peptidoglycan to form a thick structure. In addition, there are covalently bound negatively charged teichoic acids, polymers of glycerol or ribitol joined by phosphate groups, which extend out from the surface of the cell wall. They are antigenic and help mediate interactions of the cell with the environment and other microorganisms. To the interior of the cell wall, there is a periplasmic space, which has been observed in several grampositive microbes and is thought to be involved in peptidoglycan synthesis [23].

\subsubsection{Impact of Bacterial plasmids}

- $\quad$ Resistance plasmids function - Antibiotic resistance and Mercury resistance [24].

- Degradative plasmids function - 2,4-D degradation [25].

- Plant-interactive plasmids function - Tumor induction for crown gall disease nodule formation and nitrogen fixation in rhizobia [26].

- $\quad$ Fertility plasmids function - Conjugative plasmids that contain tra genes [27]

- Col plasmids function - Code for the production of colicins or proteins that kill other bacteria [28].

- Virulence plasmids function - Code for toxins in pathogenic bacteria [29].

Plasmids are DNA sequences that are separate from the chromosome. Normally, plasmids encode genes that are not mandatory for cell growth and division but that make the cell more competitive in a particular niche in the environment. Plasmids are often only retained if there is a selective pressure, such as the presence of an antibiotic, to maintain a plasmid that confers antibiotic resistance. The relationship between plasmids and the chromosome is complex because 
some plasmids can integrate into the chromosome during replication and function as part of the chromosome. During later replications, this process can be reversed, with the plasmid DNA being excised and allowed to function as a selfreplicating entity within the cell [24-29].

\subsection{Impact of Arceae}

Many archaea remain nonculturable, and this coupled with the relatively short period of time since the discovery of many archaea means that information is limited on archaean physiology, function, and the impact on global biochemical cycles. Despite this, their presence and role in extreme environments are likely to be critical. For example, it was demonstrated that archaea are capable of nitrification. Archaea have also been implicated as mediators of horizontal gene transfer between archaea and bacteria. Clearly information on the archaea will increase dramatically in the near future, particularly information on archaea found in nonextreme environments [30].

\subsection{Fungal Impact}

The $C$. albicans is the causative agent of vaginal yeast infections as well as oral thrush, a yeast infection of the mouth that commonly afflicts infants. C. albicans has a morphology similar to that of coccus bacteria; however, yeast is a eukaryotic organism and is much larger. Unicellular fungi, yeasts are included within the study of microbiology. There are more than 1000 known species. Yeasts are found in many different environments, from the deep sea to the human navel. Some yeasts have beneficial uses, such as causing bread to rise and beverages to ferment; but yeasts can also cause food to spoil. Some even cause diseases, such as vaginal yeast infections and oral thrush [31]. Figure 4 illustrated the Candida albicans and Table 2 shows the complexes containing fungi found in many distinct environments.

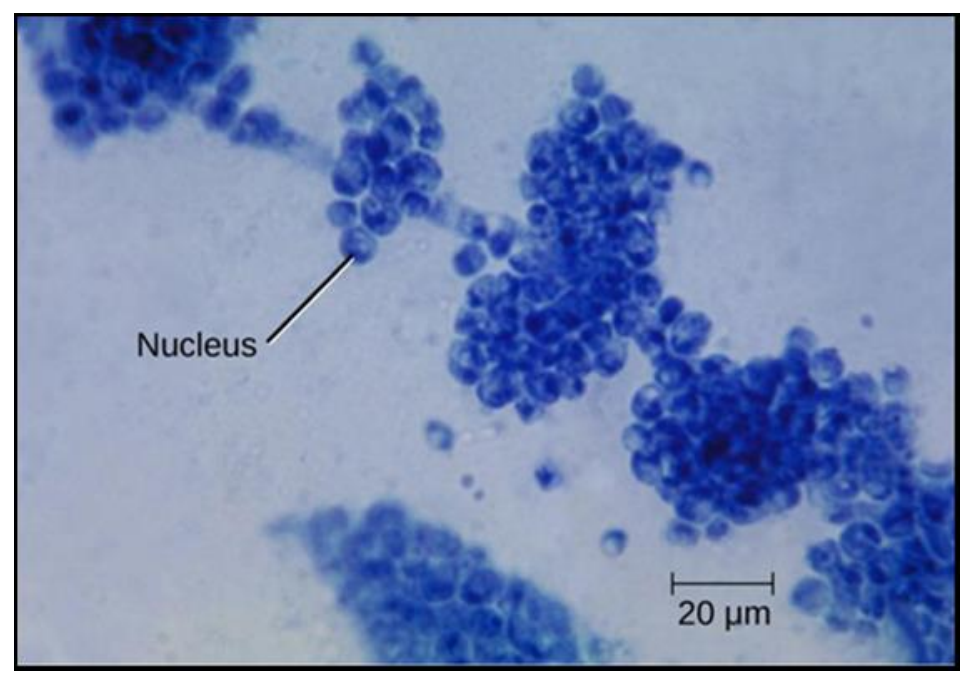

Figure 4 Candida albicans is a unicellular fungus, or yeast

Table 2 Complexes containing fungi showing many distinct environments

\begin{tabular}{|l|l|l|}
\hline \multicolumn{1}{|c|}{ Medium } & \multicolumn{1}{|c|}{ Effects } & Reference \\
\hline Human & the human oral cavity the lungs of cystic fibrosis patients & {$[31-32]$} \\
\hline Food & the production of foods such as cheese, wine, tempeh, and sourdough & {$[33]$} \\
\hline Environments & agricultural and forest environments & {$[34]$} \\
\hline
\end{tabular}

Other fungi of interest to microbiologists are multicellular organisms called molds. Molds are made up of long filaments that form visible colonies. Molds are found in many different environments, from soil to rotting food to dank bathroom corners. Molds play a critical role in the decomposition of dead plants and animals. Some molds can cause allergies, and others produce disease-causing metabolites called myco-toxins. Figure 5 shows the large colonies of microscopic fungi in moldy oranges. 


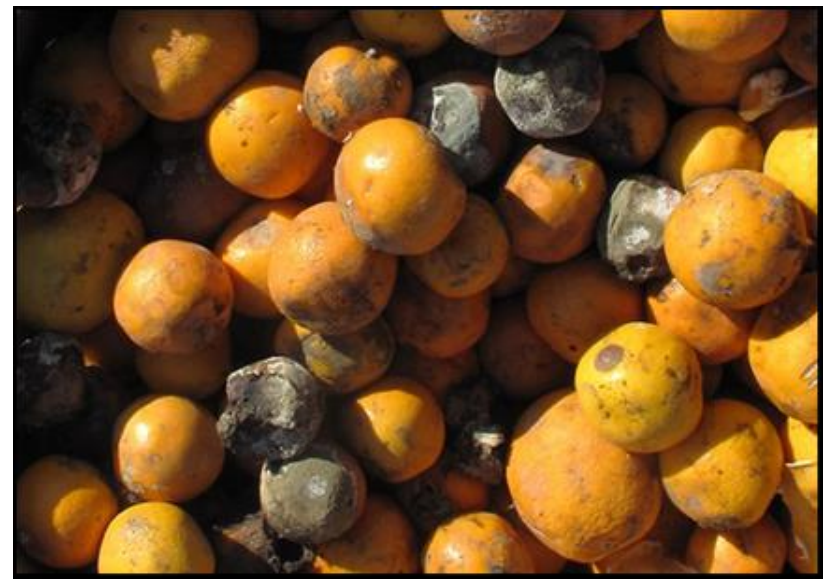

Figure 5 Large colonies of microscopic fungi can often be observed with the naked eye, as seen on the surface of the moldy oranges

\subsection{Protozoans Impact}

Since the beginning of the last century, paleoparasitology has been focused on understanding the origin and evolution of infectious diseases, relying on archaeological and paleontological material to do so. A wide diversity of intestinal parasites has been retrieved from ancient remains, primarily from helminthes [35]. Many protozoan infections that are inapparent or mild in normal individuals can be life-threatening in immunosuppressed patients, particularly patients with acquired immune deficiency syndrome (AIDS). Evidence suggests that many healthy persons harbor low numbers of Pneumocystis carinii in their lungs. However, this parasite produces a frequently fatal pneumonia in immunosuppressed patients such as those with AIDS. Toxoplasma gondii, a very common protozoan parasite, usually causes a rather mild initial illness followed by a long-lasting latent infection. AIDS patients, however, can develop fatal toxoplasmic encephalitis. Cryptosporidium was described in the 19th century, but widespread human infection has only recently been recognized. As more thorough studies of patients with AIDS are made, it is likely that other rare or unusual protozoan infections will be diagnosed. The effects of protozoa on the respiratory apparatus, as opposed to other localisations (intestine, liver, vagina, urethra, etc.), constitute a group of rare diseases, with the existence, in most cases, of an underlying clinical situation corresponding to certain states of suppressed immunity (AIDS, transplants, malign haemopathies, corticotherapy etc.), although other factors, such as visits to endemic areas and immigration, also have to be taken into account. The ecology of infectious diseases in humans entails more than the risk of acquiring an infection. It also involves the likelihood of exposure, the conditions of establishment and favourable circumstances that lead to successful transmission. While adapting to harsh environments, human populations have become part of various parasitic life cycles. For malaria, proximity to marshy areas favours the incidence of disease, as seen in the Nile Delta and the fringes of the Tiber valley. The lack of effective vaccines, the paucity of reliable drugs, and other problems, including difficulties of vector control, prompted the World Health Organization to target six diseases for increased research and training. Three of these were protozoan infections: malaria, trypanosomiasis, and leishmaniasis. Although new information on these diseases has been gained, most of the problems with control persist $[11,14,36]$.

\subsection{Impact of Viruses}

Respiratory tract infections are the most common infections to afflict mankind and are responsible for an enormous burden of disease, ranging from trivial mild common colds, to severe fatal pneumonias. It has also long been recognised that respiratory viruses associated with upper respiratory infections, such as influenza, parainfluenza, respiratory syncytial virus (RSV) and adenoviruses are also frequently associated with lower respiratory tract infections. Rhinoviruses are the commonest pathogens of the respiratory tract. Nevertheless, probably due to the benign nature of most rhinovirus colds, little attention has been paid to these viruses until recent years, when they have been implicated in acute exacerbations of asthma and chronic obstructive pulmonary disease (COPD). Several early studies sought to objectively establish a link between virus infections and asthma exacerbations [37].

Virus-microbiota interactions have been studied using several laboratory models, most commonly germ-free mice or antibiotic-treated mice. Germ-free mice are microbiologically sterile from birth and are maintained in a sterile environment. Illustrating the importance of the microbiota for nutrition, germ-free animals must consume $30 \%$ more calories per day than conventional animals to maintain body weight [38]. Table 3 demonstrated the effects of Virus. 
Table 3 Effects of Virus [1]

\begin{tabular}{|c|c|c|}
\hline Negative effects & Positive effects & Unclear effects \\
\hline $\begin{array}{ll}\text { - } & \text { Rotavirus } \\
\text { - } & \text { Influenza } \\
\text { - } & \text { Lymphocytic } \\
\text { - } & \text { Dhoriomeningitis Virus } \\
\text { Dengue Virus }\end{array}$ & $\begin{array}{l}\text { - } \text { Theiler's Murine } \\
\text { Encephalomyelitis Virus } \\
\text { - } \quad \text { Poliovirus } \\
\text { - } \quad \text { Reovirus } \\
\text { - } \quad \text { Mouse Mammary Tumor } \\
\text { Virus }\end{array}$ & $\begin{array}{ll}\text { - } & \text { Adenovirus } \\
\text { - } & \text { Coxsackievirus B3 } \\
\text { - } & \text { Norovirus and Murine } \\
& \text { Norovirus } \\
\text { - } & \text { Murine Leukemia Virus } \\
\text { - } & \text { Human } \\
\text { Immunodeficiency } \\
\text { - } \text { Hirus } \\
\text { - } & \text { Kilhaman Papillomavirus }\end{array}$ \\
\hline
\end{tabular}

\subsection{Disease of Microbes}

White-nose syndrome (WNS) is a fungal disease in bats and one of the most devastating infectious disease outbreaks in wild mammals to emerge over the past century. WNS was first detected in 2007 by biologists who discovered an abnormal mortality event at a cave in Albany County, New York (NY), USA, while conducting routine bat population monitoring surveys. Bats that were still alive were covered in a white fungus, which was most noticeable on their muzzles, ears and wings, thus leading to the disease being named WNS [39-40]. Blood protozoa, Chagas disease in the pre-columbian Americas, Trypanosoma cruzi, the causative agent of American trypanosomiasis, or Chagas disease, is transmitted through the faecal droppings of infected vectors from the subfamily Triatominae. T. cruzi is geographically restricted to the Americas and occurs primarily in Latin America, where it is endemic [54]. The effects of protozoa on the respiratory apparatus, as opposed to other localisations (intestine, liver, vagina, urethra, etc.), constitute a group of rare diseases, with the existence, in most cases, of an underlying clinical situation corresponding to certain states of suppressed immunity (AIDS, transplants, malign haemopathies, corticotherapy etc.), although other factors, such as visits to endemic areas and immigration, also have to be taken into account [14, 41]. Chart of Microorganisms Diseases are shown in Table 4.

Table 4 Chart of Microorganisms Disease (Microbes and Disease; Microbiology Society)

\begin{tabular}{|l|l|c|}
\hline \multicolumn{1}{|c|}{ Infectious disease } & Microbe that causes the disease & Type of microbe \\
\hline Fever & Dengu Virus & Virus \\
\hline Cold & Rhinovirus & Virus \\
\hline Chickenpox & Varicella zoster & Virus \\
\hline German measles & Rubella & Virus \\
\hline Whooping cough & Bordatella pertussis & Bacterium \\
\hline Bubonic plague & Yersinia pestis & Bacterium \\
\hline TB (Tuberculosis) & Mycobacterium tuberculosis & Bacterium \\
\hline Malaria & Plasmodium falciparum & Protozoan \\
\hline Ringworm & Trichophyton rubrum & Fungus \\
\hline Athletes' foot & Trichophyton mentagrophytes & Fungus \\
\hline
\end{tabular}

Influenza viruses are enveloped viruses of the Orthomyxoviridae family, which are classified into four genera, which include influenza virus A-D (IAV, IBV, ICV and IDV) and coronaviruses are enveloped single-stranded nonsegmented RNA viruses of the Coronaviridae family, subfamily Coronavirinae, which are further subdivided into four genera based on phylogenetic analyses: alpha coronaviruses, beta coronaviruses, gamma coronaviruses and delta coronaviruses. Similarly, to influenza viruses, coronaviruses circulate within non-human reservoirs. Mammalian coronavirus infection 
is predominantly caused by alpha coronaviruses and beta coronaviruses, which share bats and rodents as natural reservoirs [42].

\subsection{Impact on Environment and Living Things}

Microbes are everywhere in the biosphere, and their presence invariably affects the environment that they are growing in. The effects of microorganisms on their environment can be beneficial or harmful or in apparent with regard to human measure or observation. The beneficial effects of microbes derive from their metabolic activities in the environment, their associations with plants and animals, and from their use in food production and biotechnological processes. The most significant effect of the microorganisms on earth is their ability to recycle the primary elements that make up all living systems, especially carbon (C), oxygen (O) and nitrogen (N). These elements occur in different molecular forms that must be shared among all types of life. Different forms of carbon and nitrogen are needed as nutrients by different types of organisms. The diversity of metabolism that exists in the microbes ensures that these elements will be available in their proper form for every type of life [17]. Acanthamoeba species are free-living amebas that inhabit soil and water. Cyst stages can be airborne. Serious eye-threatening corneal ulcers due to Acanthamoeba species are being reported in individuals who use contact lenses. The parasites presumably are transmitted in contaminated lens-cleaning solution. Amebas of the genus Naegleria, which inhabit bodies of fresh water, are responsible for almost all cases of the usually fatal disease primary amebic meningoencephalitis. The amebas are thought to enter the body from water that is splashed onto the upper nasal tract during swimming or diving. Human infections of this type were predicted before they were recognized and reported, based on laboratory studies of Acanthamoeba infections in cell cultures and in animals. Nitrogen fixation is a process found only in some bacteria which removes N2 from the atmosphere and converts it to ammonia (NH3), for use by plants and animals. Nitrogen fixation also results in replenishment of soil nitrogen removed by agricultural processes. Some bacteria fix nitrogen in symbiotic associations in plants. Other Nitrogen-fixing bacteria are free-living in soil and aquatic habitats [22]. The Cyanobacterium, Synechococcus, is a primary component of marine and freshwater plankton and microbial mats. The unicellular procaryote is involved in primary production, nitrogen fixation and oxygenic photosynthesis and thereby participates in the cycles of carbon, nitrogen and oxygen. Synechococcus is among the most important photosynthetic bacteria in marine environments, estimated to account for about 25 percent of the primary production that occurs in typical marine habitats [43].

Environmental studies need to understand the life processes at the microscopic level and ecologist levels from species to ecosystem. Species refer to organisms of the same kind that are genetically similar enough to breed in nature and produce live, fertile offspring. The primary harmful effects of microbes upon our existence and civilization is that they are an important cause of disease in animals and crop plants, and they are agents of spoilage and decomposition of our foods, medicine, textiles and dwellings. Microbial spoilage can be caused by bacteria, yeasts or fungi which are all extremely versatile in their metabolic activities. This capacity for variation, whether due to mutation in genetic composition followed by selection or to changes in behaviour unaccompanied by genetichange, allows adaptation to a very broad range of environmental condition [44]. Table 5 illustated the types of Spoilage. Microbes are also the cause of many diseases in plants, which, if crop plants or forest resources, may have important economic or social [23, 26, 37 , 43].

Table 5 Types of Spoilage

\begin{tabular}{|l|l|l|l|}
\hline \multicolumn{1}{|c|}{ Based on rate of spoilage } & \multicolumn{2}{|c|}{ Types of microbial spoilage } \\
\hline Highly Perishable: & Physio-chemical & Chemical & Biological \\
\cline { 2 - 4 } $\begin{array}{l}\text { Meat, Fish, Egg, Milk, Most } \\
\text { fruits and Vegetables. }\end{array}$ & Viable growth & Hydrolysis & Release of Toxins \\
\cline { 4 - 4 } Semi Perishable: Aas production & Acetylation & Microbial \\
Potatoes, Some Apple & Physical spoilage & Depolymerization & \\
Varities, Nut meats & Olfactory & Degradation/ & Metabolisation \\
\cline { 1 - 1 } $\begin{array}{l}\text { Non-perishable or Stable: } \\
\text { Sugar, Flour and Dry Beans. }\end{array}$ & & & \\
\hline
\end{tabular}

A microbe which is capable of causing infectious disease in an animal or plant is called a pathogen. Four groups of microbes contain pathogens: bacteria, fungi, protozoa and the viruses. Only the archaea and algae are lacking pathogens. Pathogens are the cause of infectious diseases. 
- Bacterial diseases such as tuberculosis, typhus, plague, diphtheria, typhoid fever, cholera, dysentery and pneumonia have taken a huge toll on humanity.

- In 1900, the three leading causes of death were pneumonia, tuberculosis (TB), and diarrhea and enteritis, which (together with diphtheria) caused one third of all deaths. In 1997, heart disease and cancers accounted for 55\% of all deaths, with $4.5 \%$ attributable to pneumonia, influenza, and human immunodeficiency virus (HIV) infection.

- Water purification, immunization (vaccination), and modern antibiotic therapy (all developments in the field of bacteriology) have dramatically reduced the morbidity and the mortality of infectious disease during the Twentieth Century, at least in the developed world where these are acceptable cultural practices. However, many new microbial pathogens have been recognized in the past 30 years and many "old" bacterial pathogens, such as Staphylococcus aureus and Mycobacterium tuberculosis, have emerged with new forms of virulence and new patterns of resistance to antimicrobial agents.

\section{Application}

Microorganisms are widely distributed on the biosphere because of their metabolic ability is very impressive and they can easily grow in a wide range of environmental conditions. The nutritional versatility of microorganisms can also be exploited for biodegradation of pollutants. This kind of process is termed as bioremediation. It is continued through based on the ability of certain microorganisms to convert, modify and utilize toxic pollutants in order to obtaining energy and biomass production in the process [45]. Instead of simply collecting the pollutant and storing it, bioremediation is a microbiological well organized procedural activity which is applied to break down or transform contaminates to less toxic or non-toxic elemental and compound forms. Bioremediators are biological agents used for bioremediation in order to clean up contaminated sites. Bacteria, archaea and fungi are typical prime bioremediators [46].

\subsection{Microbiological Analysis}

\subsubsection{Water Analysis}

The principles of the microbiological analysis of water have evolved over nearly a century and are important tools for the protection of public health all over the world. The microbiological analysis of water aims at a great variety of microorganisms, including viruses, bacteria, and protozoa. The target organisms may be pathogenic to man or they may be harmless model organisms. The different purposes of the sanitary microbiological analysis of water are described in the section on applications [47].

\subsubsection{Water Quality Control}

Water problems may arise in maintaining consistent treatment and disinfection because of lack of resources, inadequate supplies of materials, or lack of skills in the local labour force. However, every effort should be made to provide consumers with a palatable and aesthetically pleasing water supply that is free of bacteria, harmful chemicals and objectionable tastes or odours, especially if the alternative is an untreated source of doubtful quality. Where possible, analysis for the recognized indicator organisms, coliform bacteria and Escherichia coli should be carried out preferably daily, but at least weekly, on samples of treated water leaving the water treatment works [48].

\subsubsection{Food Analysis}

The microbiological analysis of food is part of food safety management and conformity tests that define microbiological criteria or assess the performance of control strategies based on the Hazard Analysis and Critical Control Point. Bacteria stand out the most, both as pathogens and as spoilage microorganisms. For example, Pseudomonas spp. and other Gramnegative psychrotrophic microorganisms can be responsible for reduction of shelf life of high-protein, chilled foods stored under aerobic conditions, such as meat and dairy products. Pseudomonas is associated with postprocessing contamination of pasteurized milk. Shewanella putrefaciens is an example of psychrotrophic microorganism responsible for the deterioration of chilled seafood. Although vegetative forms of microorganisms play an important role in food spoilage, spore-forming bacteria are of great relevance for processed food, such as canned foods, vacuum-packaged meat, and thermally processed foods, because their spores survive lethal treatments [49].

\subsubsection{Food Safety Management}

The ability of microorganisms to grow in food, pharmaceutical and cosmetic products has been identified for many years and it has been the subject of debates for years. From the infectious point of view, the existence of pathogenic microbes in pharmaceutical and food products makes them hazardous and would objectionable. Many technologies have been 
developed in food and pharmaceutical microbiology laboratories in the recent century to sensitive, precise, and quick microbial detection. When interpreting sample results, the analyst or supervisor uses control results to confirm the validity of positive or negative findings. For example, in microbiological analysis, a positive control confirms that the target bacteria the media supports able to grow; bacteria that are not desired to grow in fact inhibited and that the uninoculated media, buffers, or water used during the analysis are sterile. Generally, rapid methods include some forms of automation to obtain data of quantity and quality of microbes present in the sample. Applying rapid methods would help companies for saving time and cost. To better and faster control of raw materials and final products, rapid microbiological methods are essential. These rapid methodologies can also offer a better reactivity throughout the manufacturing procedure [50].

\subsection{Public Health}

\subsubsection{Protozoa}

Unlike enteric protozoa, blood protozoa have historically attracted the interest of more researchers, primarily because of their epidemiological importance in public health. The use of molecular techniques has enabled confirmation of Chagas disease in Andean mummies dating back to 9000 BP and falciparum malaria in ancient Egyptian mummies dating to $5200 \mathrm{BP}$. Although many of the protozoa that are of medical interest may be cultivated, this technique is little used for diagnostic purposes, enhancing the importance of microscopic visualisation. This may be achieved either by fresh examination or by the employment of specific stains (Wheatley's trichromic, Giemsa, Heidenhain, Lugol, etc.). Furthermore, together with the electron microscope, there exist more specific diagnostic methods based on immunological analysis or molecular biology tests $[14,51]$. It is worth noting that malaria antigen detection tests are not as sensitive as microscopy. Although some researchers have been able to recover $P$. falciparum histidine-rich protein 2 using the ParaSight ${ }^{\mathrm{TM}}$-F test, some of these results were not reproducible in further investigations [52].

\subsubsection{Virus}

If a survey were to ask nonvirologists for their opinions about viruses, the word "good" would be unlikely to arise. Instead, words such as "disease," "infection," "suffering," or "life-threatening" would likely dominate, as people primarily think of viruses such as HIV, Ebola virus, Zika virus, Influenza virus, or whatever new outbreak is in the news. However, as we are now finding out, not all viruses are detrimental to human health. In fact, some viruses have beneficial properties for their hosts in a symbiotic relationship, while other natural and laboratory-modified viruses can be used to target and kill cancer cells, to treat a variety of genetic diseases as gene and cell therapy tools, or to serve as vaccines or vaccine delivery agents [53]. Currently, multiple phase I to phase III clinical trials are ongoing for the treatment of various cancer types, including hepatocellular carcinoma, glioblastoma multiforme, colorectal cancer, and cancers of the lung, breast, prostate, pancreas, bladder, and ovaries. In 2015, the first oncolytic virus therapy based on a herpesvirus was approved by the US Food and Drug Administration and European Medicines Agency for the treatment of melanoma lesions in the skin and lymph nodes [54].

\subsubsection{Antibiotics}

Antibiotics chemical substance produced by a living organism, generally a microorganism that is detrimental to other microorganisms. Antibiotics commonly are produced by soil microorganisms and probably represent a means by which organisms in a complex environment, such as soil, control the growth of competing microorganisms. Microorganisms that produce antibiotics useful in preventing or treating disease include the bacteria and the fungi. Antibiotics are substances produced by microorganisms that kill or inhibit other microbes which are used in the treatment of infectious disease. Antibiotics are produced in nature by molds such as Penicillium and bacteria such as Streptomyces and Bacillus. Molds have been used to make pharmaceuticals, including penicillin, which is one of the most commonly prescribed antibiotics, and cyclosporine, used to prevent organ rejection following a transplant [55].

A21978C is an amphipathic acidic Ca2+-dependent lipopeptide antibiotic complex produced by Streptomyces roseosporus. A21978C is composed of a tenmembered cyclic peptide coupled by an ester bond between the C-terminus of kynurenine (Kyn13) and the hydroxyl group of Thr4. A21978C has a three amino acid exocyclic tail coupled by an amide linkage of the $\mathrm{N}$-terminus of Trp1 to different fatty acids. The fatty acids can be removed enzymatically by a deacylase produced by Actinoplanes utahensis. Tn5099 was used to physically map genes involved in daptomycin and red pigment production in Streptomyces roseosporus. IS493 is a $1.6 \mathrm{~kb}$ insertion sequence (IS) element that was isolated from Streptomyces lividans by its ability to transpose into a novel transposon trap [56]. 


\subsubsection{Vaccines}

Vaccines are made from microbes that are dead or inactive so that they are unable to cause disease. The antigen in the vaccine is the same as the antigen on the surface of the disease-causing microbe. The vaccine stimulates the body to produce antibodies against the antigen in the vaccine. The antibodies created will be the same as those produced if the person was exposed to the pathogen. Vaccines are usually given by an injection. The measles vaccine is combined with the mumps and rubella (German measles) vaccines and is given as a single injection to babies at at 12-18 months, and again at four years old. It is called the MMR vaccine. When enough people are vaccinated against a disease it is possible for that disease to be eliminated from the world, e.g. in 1980 the World Health Organization announced that smallpox had been eradicated. [Form: Copyright (C) 2021 Microbiology Society. Registered as a Charity in England and Wales 264017. A Charity registered in Scotland SC039250. Company Limited by Guarantee. Registered in England 1039582].

Vaccines are substances derived from microorganisms used to immunize against disease. The microbes that are the cause of infectious disease are usually the ultimate source of vaccines. Thus, a version of the diphtheria toxin (called toxoid) is used to immunize against diphtheria, and parts of Bordetella pertussis cells are used to vaccinate against pertussis (whooping cough). The use of vaccines such as smallpox, polio, diphtheria, tetanus and whooping cough has led to virtual elimination of these diseases in regions of the world where the vaccines have been deployed [43]. While antibiotics are used to treat microbial infections, vaccines are used to prevent infections. Vaccines can work by using parts of the pathogen or a whole inactive pathogen to stimulate the immune system. The measles, mumps and rubella (MMR) vaccine consists of all three live attenuated viruses mentioned above. Two other examples of live attenuated vaccines are Poliovirus vaccine that prevents poliomyelitis and Bacillus Calmette-Guérin (BCG) vaccine that prevents tuberculosis caused by Mycobacterium tuberculosis. Some diseases such as tetanus and diphtheria are mainly the result of toxins produced by the micro-organisms. Tetanus, an awful condition caused by Clostridium tetani that enters your body if you have an injury, is the direct result of the tetanus toxin released by the bacteria. Tetanus toxin, inactivated by formalin, is the vaccine given to protect against tetanus. The tetnus toxoid vaccine is produced by growing the bacteria in culture and harvesting the toxin. So here, two main ways of destroying disease-causing microbes: by using microbial poisons such as antibiotics that are produced by microbes themselves, and by using vaccines to prime the body's immune system to be ready for an infection. In the next installment, "The World of Microbes, Part 2" "the good bacteria in your gut." That's right, it time to learn about your gut friends that fight pathogens, keep your immune system up to snuff and help you digest food.

\subsection{Dairy products}

Fermented dairy products are an important part of our diet and can contain a diverse microbiota. Lactic acid bacteria (LAB) are the main players during milk fermentation, converting lactose to lactic acid, which results in an increased acidity that makes growth conditions of microorganisms other than LAB increasingly unfavourable. The most common LAB present in milk includes species belonging to the genera Lactobacillus, Streptococcus, Leuconostoc, Enterococcus, and Lactococcus [57]. Fermentation is anaerobic process that uses only substrate level phosphorylation with a net generation of 2 ATP per glucose. Instead, electrons are shunted among organic compounds usually ending in the production of organic acids or alcohols and resulting in very small amounts of energy. Thus, in fermentation, the end products include a combination of $\mathrm{CO} 2$ and organic acids and alcohols.

Fermentation:

$$
\mathrm{C}_{2} \mathrm{H}_{5} \mathrm{OH}+\mathrm{CO}_{2} \rightarrow 1.5 \mathrm{CH}_{3} \mathrm{COOH} \Delta \mathrm{G}^{0}\left(25^{\circ} \mathrm{C}\right)=-27.45 \mathrm{KJ} / \mathrm{mol}
$$

Fermentation is a process that has been taken widely advantage of in the manufacture of alcoholic beverages and a variety of other food products (vinegar, olives, yogurt, bread, cheese). All of the preceding reactions illustrate how organisms mediate reactions involved in biogeochemical cycling of carbon, nitrogen, and sulfur [58].

\subsection{Environment}

Environmental studies need to understand the life processes at the microscopic level and ecologist levels from species to ecosystem. Species refer to organisms of the same kind that are genetically similar enough to breed in nature and produce live, fertile offspring. Such as

- The surface soil is always rich in indigenous population of bacteria (including actinomycetes), fungi, algae, and protozoans.

- Rain forests are the most diverse and productive terrestrial microenvironment, but their soil is nutrient deficient due to extensive leaching by rainwater. 
- Most of the gram-negative bacteria associated with aerosols are able to survive for longer period at low relative humidity, whereas in contrast gram-positive bacteria remain viable longer in association with high relative humidity. The ability of microbes to survive in aerosol is related to the organism's surface biochemistry.

- Lentic habitats are dominated by phytoplankton, forming distinct community gradients based upon the wavelength and the amount of light that penetrates to a depth, e.g., Chlorobium. Chlorobium can utilize longer wavelength than other phototrophs and survive with little or no oxygen by consuming $\mathrm{H}_{2} \mathrm{~S}$ instead of $\mathrm{H}_{2} \mathrm{O}$ for photosynthesis.

Microbial inoculants or biofertilizers are live or latent cell of strains that are efficient in phosphate solubilization, nitrogen fixation, potassium solubilization, siderophore production used for seed application, soil or composting areas where such microorganism population can increase and enhance several microbial processes to boost the nutrients availability that can be utilised by plants. The history of applying microbial inoculums have passed down generations of farmers. The efficacy of biofertilizers was evident when on small scale culture compost was introduced, it enhanced the decomposition of organic residues and agriculture by-products that resulted in healthy harvest of crops. Rhizobium inoculation is well known agronomic practice to ensure adequate nitrogen of legumes instead of N-fertilizer. This is only produced when the plant is infected with Rhizobium. The plant root cells convert sugar to organic acids which they supply to the bacteroids. In exchange, the plant will receive amino-acids rather than free ammonia. Azotobacter is a typical mesophilic organism and most researchers regard $25-30^{\circ} \mathrm{C}$ as the optimum temperature for Azotobacter (Mishustin and Shilnikova, 1969). At high temperature between 45-48으, vegetative Azotobacter cells cannot tolerate and will degenerated and dies [59-60].

\section{Conclusion}

The present world is terrified of germs. Knowing the knowledge of microbiology is vital to protect the environment and even to ensure food safety in order to protect oneself from this great threat. Microorganisms are pervasive and influential throughout every major environment. In fact, any environment that is devoid of microorganisms is certainly the exception and not the rule. Microorganisms are fundamental to all ecosystems, providing the biotic foundation upon which all life exists. Unfortunately, the general public most often perceives microorganisms primarily as the etiological agents of disease. In many cases the opposite is true, and many microbes are, in fact, beneficial. Regardless of whether they influence human health and welfare favorably or unfavorably, microorganisms are capable of profound influences on life as we know it. Wherefores, it has become essential for us to make proper use of their beneficial aspects and apply them for human welfare.

\section{Compliance with ethical standards}

\section{Acknowledgments}

The research work was supported by the Annual Development Project (ADP) of Bangladesh. The title of the project is: "Strengthening of existing gamma source of Bangladesh Atomic Energy Commission". Special thanks to The Ministry of Science and Technology and The Ministry of Planning, Government of the People's Republic of Bangladesh.

\section{Disclosure of conflict of interest}

All authors state that there is no conflict of interest.

\section{References}

[1] Christopher M. Robinson and Julie K. Pfeiffer, Viruses and the Microbiota. Annu. Rev. Virol. 2014; 1, 55-69.

[2] Leonie Dries, Simone Bussotti, Carlo Pozzi, Robert Kunz, Sylvia Schnell, Otmar Löhnertz and Anne Vortkamp, Rootstocks Shape Their Microbiome-Bacterial Communities in the Rhizosphere of Different Grapevine Rootstocks. Microorganisms. 2021; 9: 1-12.

[3] Seth R Bordenstein, Kevin R Theis. Host Biology in Light of the Microbiome: Ten Principles of Holobionts and Hologenomes. PLOS Biology. 2015; 13: 1-23.

[4] Woyke T, Rubin EM. Evolution. Searching for new branches on the tree of life. Science. 2014; 346: 698-699.

[5] John A Fuerst. Microorganisms-A Journal and a Unifying Concept for the Science of Microbiology. Microorganisms. 2014; 2: 140-146. 
[6] Cuvelier ML, Allen AE, Monier A, McCrow JP, Messié M, Tringe SG, Woyke T, Welsh RM, Ishoey T, Lee JH. Targeted metagenomics and ecology of globally important uncultured eukaryotic phytoplankton. Proc. Natl. Acad. Sci. 2010; 107: 14679-14684.

[7] Breitbart M, Salamon P, Andresen B, Mahaffy JM, Segall AM, Mead D, Azam F, Rohwer F. Genomic analysis of uncultured marine viral communities. Proc. Natl. Acad. Sci. U. S. A. 2002; 99: 14250-14255.

[8] Maier RM, Drees KP, Neilson JW, Quade J, Henderson DA, Betancourt JL. Microbial life in the Atacama Desert. Science. 2004; 306: 1289-1290.

[9] Schloss PD, Handelsman J. Status of the microbial census. Microbiol. Mol. Biol. Rev. 2004; 68: 686-691.

[10] Timberley M. Roane, Kelly A. Reynolds, Raina M. Maier and Ian L. Pepper (2009) Microorganisms. Environmental Microbiology. 9-39.

[11] Giovannoni SJ, Stingl U. Molecular diversity and ecology of microbial plankton . Nature. 2005; 427: 343-348.

[12] Cavicchioli R, Curmi P, Saunders N, Thomas T. Pathogenic archaea: do they exist?. Bioessays. 2003; 25: 11191128.

[13] Crous PW, Rong IH, Wood A, Lee S, Glen H, Botha W, Slippers B, de Beer WZ, Wingfi eld MJ, Hawksworth DL. How many species of fungi are there at the tip of Africa?. Studies in Mycology. 2006; 55: 13-33.

[14] R Martı́nez-Giro'n, JG Esteban\#, A Ribas, L Doganci. Protozoa in respiratory pathology: a review. European Respiratory Journal. 2008; 32: 1354-1370.

[15] Rohwer F, Thurber RV. Viruses manipulate the marine environment. Nature. 2009; 459: 207-212.

[16] Suttle CA. Marine viruses-Major players in the global ecosystem. Nat. Rev. Microbiol. 2007; 5: 801-812.

[17] Ankit Gupta, Rasna Gupta, Ram Lakhan Singh. Microbes and Environment; Principles and Applications of Environmental Biotechnology for a Sustainable Future. 2016; 3: 43-84.

[18] Diriba Girmaye, Debela Abdeta, Yobsan Tamiru. Review on Bacterial Biofilms and its impact. Int.J.Adv.Microbiol.Health.Res. 2018; 2: 22-30.

[19] Shi X, Zhu X. Biofilm formation and food safety in food industries. Trends Food Sci. Tech. 2009; 20: 407-413.

[20] Loo CY. Oral Streptococcal genes that encode biofilm formation. Med.Implic.of Biofilms. 2003; 1: 212-227.

[21] Baldassarri L, Cecchini R, Bertuccini L, Ammendolia MG, Iosi F, Arciola CR, et al. Enterococcus spp. produces slime and survives in rat peritoneal macrophages. Med. Microbiol. and Immunol. 2001; 190: 113-120.

[22] Garcia AB, Percival SL. Zoonotic infections: The role of biofilm. Biofilm Vet. Med. 2011; 6: 69-110.

[23] Matias VR, Beveridgeb TJ. Native cell wall organization shown by cryo-electron microscopy confi rms the existence of a periplasmic space in Staphylococcus aureus; J. Bacteriol. 2006; 188: 1011-1021.

[24] Brooks JP, Rusin PA, Maxwell SL, Rensing C, Gerba CP, Pepper IL. Occurrence of antibiotic-resistant bacteria and endotoxin associated with the land application of biosolids. Can. J. Microbiol. 2007; 63: 616-622.

[25] Newby DT, Josephson KL, Pepper IL. Detection and characterization of plasmid pJP4 transfer to indigenous soil bacteria. Appl. Environ. Microbiol. 2000; 66: 290-296.

[26] Rogel MA, Hernandez-Lucas I, Kuykendall D, Balkwill DL, Martinez-Romero E. Nitrogen-fi xing nodules with Ensifer adhaerens harboring Rhizobium tropici symbiotic plasmids. Appl. Environ. Microbiol. 2001; 67: 32643268.

[27] Van Biesen T, Frost LS. Different levels of fertility inhibition among F-like plasmids are related to the cellular concentration of fi nO mRNA. Mol. Microbiol. 1992; 6: 771-780.

[28] Riley MA, Gordon DM. A survey of Col plasmids in natural isolates of E.coli and an investigation into the stability of Colplasmid linages. J. Gen. Microbiol. 1992; 138: 1345-135.

[29] Sayeed S, Li J, McClane BA. Virulence plasmid diversity in Clostridium perfringens Type D isolates. Infect. Immun. 2007; 75: 2391-2398.

[30] Konneke M, Bernard AE, de la Torre JR, Walker CB, Waterbury JB, Stahl DA. Isolation of an autotrophic ammoniaoxidizing marine archaeon. Nature. 2005; 437: 543-546. 
[31] Bauernfeind A, et al. Qualitative and quantitative microbiological analysis of sputa of 102 patients with cystic fibrosis. Infection. 1987; 15: 270-277.

[32] Avila M, DM Ojcius, O Yilmaz. The oral microbiota: living with a permanent guest. DNA Cell Biol. 2009; 28: 405411.

[33] Wood BJB. Microbiology of fermented foods. Springer, Berlin, Germany; $2^{\text {nd }}$ ed. 1997.

[34] Frey-Klett P, J Garbaye, M Tarkka. The mycorrhiza helper bacteria revisited. New Phytol. 2007; 176: 22-36.

[35] Gonçalves MLC, Araújo A, Duarte R, Pereira da Silva J, Reinhard K, Bouchet F, Ferreira LF. Detection of Giardia duodenalis antigen in coprolites using a commercially available enzyme-linked immunosorbent assay. Trans $R$ Soc Trop Med Hyg. 2002; 96: 640-643.

[36] Sallares R, Gomzi S. Biomolecular archaeology of malaria. Anc. Biomol. 2001; 3: 195-213.

[37] SL Johnston. Impact of viruses on airway diseases. Eur. Respir. Rev. 2005; 14: 57-61.

[38] Wostmann BS, Larkin C, Moriarty A, Bruckner-Kardoss E. Dietary intake, energy metabolism, and excretory losses of adult male germfree Wistar rats. Lab. Anim. Sci. 1983; 33: 46-50.

[39] Frick WF, et al. Disease alters macroecological patterns of North American bats. Glob. Ecol. Biogeogr. 2015; 24: 741-749.

[40] Meteyer CU, et al. Histopathologic criteria to confirm white-nose syndrome in bats. J. Vet. Diagn. Invest. 2009; 21 : 411-414.

[41] Moncayo A, Silveira AC. Current epidemiological trends for Chagas disease in Latin America and future challenges in epidemiology, surveillance and health policy. Mem Inst Oswaldo Cruz. 2009; 104: 17-30.

[42] Tim Flerlage, David F. Boyd, Victoria Meliopoulos, Paul G. Thomas Stacey Schultz-Cherry. Influenza virus and SARS-CoV-2: pathogenesis and host responses in the respiratory tract. Nature Reviews Microbiology. 2021; 1-14.

[43] Kenneth Todar. The Impact of Microbes on the Environment and Human Activities; Todar's Online Textbook of Bacteriology. 2015; 1-4.

[44] R. Smart, DF Spooner. Microbiological spoilage in pharmaceuticals and cosmetic. J. Soc. Cosmet. Chem. 1972; 23: 721-737.

[45] Tang CY, Criddle QS Fu CS, Leckie JO. Effect of flux (trans membrane pressure) and membranes properties on fouling and rejection of reverse osmosis and nano filtration membranes treating perfluorooctane sulfonate containing waste water. J Enviro Sci Tech. 2007; 41: 2008-2014.

[46] Strong PJ, Burgess JE. Treatment methods for wine-related ad distillery wastewaters: a review. Biorem J. 2008; 12: 70-87.

[47] FM Schets, AM de Roda Husman, AH Havelaar. Water Analysis/ Microbiological. Encyclopedia of Analytical Science. 2005; (2nd Edition): 336-343.

[48] Malcolm J. Brandt BSc, FICE, FCIWEM, MIWater, Don D. Ratnayaka BSc, DIC, MSc, FIChemE, FCIWEM. Chemistry, Microbiology and Biology of Water. Twort's Water Supply. 2017; (7th Edition): 235-321.

[49] HM Húngaro, WEL Peña, NBM Silva and RV Carvalho, VO Alvarenga, AS Sant'Ana. Food Microbiology. Encyclopedia of Agriculture and Food Systems. 2009; 3: 213-231.

[50] Mahboob Nemati, Aliasghar Hamidi, Solmaz Maleki Dizaj, Vahid Javaherzadeh, Farzaneh Lotfipour. An Overview on Novel Microbial Determination Methods in Pharmaceutical and Food Quality Control. Adv Pharm Bull. 2016; 6(3): 301-308.

[51] Aufderheide AC, Salo W, Madden M, Streitz J, Buikstra J, Guhl F, Arriaza B, Renier C, Wittmers LE Jr, Fornaciari G, Allison M. A 9,000-year record of Chagas disease. Proc Natl Acad Sci USA. 2004; 101: 2034-2039.

[52] Taylor GM, Rutland P, Molleson T. A sensitive polymerase chain reaction method for the detection of Plasmodium species DNA in ancient human remains. Anc Biomol. 1997; 1: 193-203.

[53] Roossinck MJ. The good viruses: viral mutualistic symbioses. Nat. Rev. Microbiol. 2011; 9: 99-108.

[54] Mario Mietzsch and Mavis Agbandje-McKenna. The Good That Viruses Do; Annu. Rev. Virol. 2007; 4: 3-5.

[55] Jerome L. Fechtner, DDS, Plainfield NJ. Fungi and Bacteria Antibiotics: A Review, Jou r. A .D .A . 1994; 31: 12171225. 
[56] Richard H. Baltz Æ Paul Brian Æ Vivian Miao Stephen K. Wrigley. Combinatorial biosynthesis of lipopeptide antibiotics in Streptomyces roseosporus, J Ind Microbiol Biotechnol. 2006; 33: 66-74.

[57] L Quigley, O O'Sullivan, TP Beresford, RP Ross, GF Fitzgerald, PD Cotter. Molecular approaches to analysing the microbial composition of raw milk and raw milk cheese, International Journal of Food Microbiology. 2011; 150: 81-94.

[58] Amend JP, Shock EL. Energetic of overall metabolic reactions of thermophilic and hyperthermophilic Archaea and Bacteria. FEMS Microbiol. Rev. 2001; 25: 175 -243.

[59] Abdul Halim NB. Effects of using enhanced biofertilizer containing N-fixer bacteria on patchouli growth. Thesis. Faculty of Chemical and Natural Resources Engineering University Malaysia Pahang. 2009; 145: 1-77.

[60] M Monib, Y Abd-el-Malek, I Hosnya, M Fayez. Effect of Azotobader inoculation on plant growth and soil nitrogen. Zbl. Bakt. II. Abt. 1979; 134: 140-148. 